\title{
Anxiety and Psychological Stress during COVID-19 Pandemic among the Students of Faculty of Medicine, Suez Canal University, Egypt
}

\author{
Enayat M. Soltan ${ }^{1 *}$, Hend M. Salama ${ }^{1}$, Safaa M. El-Zoghby ${ }^{1}$ \\ ${ }^{1}$ Family Medicine Department, Faculty of Medicine, Suez Canal University
}

\begin{abstract}
:
Background: Outbreaks can impose considerable psychological stress that may lead to unpredictable negative outcomes on learning, performance, and overall psychological wellbeing. Objectives: This study aimed to investigate anxiety and psychological stress during the COVID-19 pandemic among the students of Faculty of Medicine, Suez Canal University, Egypt. Methods: A cross-sectional analytic descriptive design was used. About 381 medical students from Suez Canal University agreed to complete an anonymous online survey to collect demographic data, 7-item Generalized Anxiety Disorder questionnaire (GAD-7), and General Health Questionnaire-12 (GHQ-12) to assess anxiety and psychological stress, respectively. The survey was conducted during the summer of 2020. Results: Out of the study participants, $82.4 \%$ and $64 \%$ were screened positive for anxiety and psychological stress, respectively. The students in clinical years have a higher level of anxiety $(\mathrm{P}=0.017)$ and stress $(\mathrm{P}=0.004)$ compared to the students in pre-clinical years. Conclusion: COVID-19 has harmful psychological consequences on medical university students.
\end{abstract}

Keywords: Anxiety; Covid-19; Stress; Medical students.

\section{Introduction:}

The World Health Organization (WHO) declared the novel coronavirus disease 2019 (COVID-19) as a global health emergency and pandemic in January 2020. This virus has led to dramatic harmful consequences on life style, family dynamics as well as physical, mental, and social health. This virus is unpredictable, causing stress, anxiety, fear, and depression in children and adults, especially healthcare providers. ${ }^{(1)}$

Most of the countries facing this pandemic have established obligatory preventive precautions to decrease viral infection spread including the closure of shopping malls, religious ceremonies, cinemas, sports venues, schools, universities, and staying at home to decrease the number of infections. ${ }^{(2)}$ Since then, many universities across the world have decided to shift most of their existing learning plans to online/e-learning courses. Medical faculties were not an exception as they also experienced this transition where activities were confined to distance and digital learning and clinical rotations were suspended. ${ }^{(3)}$

This transition from normal daily educational activities at university to staying at home along with curfews and social distance could affect students. (4) Therefore, medical students are living through exceptional hard times where their education is interrupted and they begin to experience stress, anxiety, and confusion. ${ }^{(5)}$

It has been established that outbreaks can impose considerable psychological 
stress that may lead to negative effects on learning and the overall psychological wellbeing of students. ${ }^{(6)}$

While the world has drawn global intensive attention to fighting this virus, taking care of people's mental health should not be ignored. ${ }^{(7)}$ Therefore, this present study aims to examine anxiety and psychological stress among medical students facing the COVID-19 pandemic.

\section{Methods:}

\section{Design, setting, and time of research:}

A cross-sectional, descriptive, and analytic design was used for the present study which was conducted at Suez Canal University in the summer of 2020.

\section{Study population:}

The study was conducted among Suez Canal University students in the summer of 2020 using the convenience sampling technique. We used www.openepi.com to calculate the sample size which resulted in 344 students, maintaining an expected frequency of $33.8 \% \%$ based on a research which estimated the global prevalence rate of anxiety among medical students to be $33.8 \%$, while confidence interval was $95 \%$ and absolute precision was 5\%. ${ }^{(8)}$ The sample size extended to be 381 students.

\section{Inclusion and exclusion criteria:}

Medical undergraduate students (from both genders in Suez Canal University who can submit the research were included. We excluded any student aged less than 18 years old.

\section{Tools of the study:}

The survey consisted of 2 sections. The first section is a consent form and the second section is divided into 3 parts; the first part contained sociodemographic data questions (age, gender, study year, smoking status, illicit drug use, presence of any chronic illness, and current contact with suspected COVID-19 patients), and the second part contained the generalized anxiety disorder scale (GAD-7).

This scale is a 7-question scale asking university medical students how often they felt each symptom such as feeling nervous, trouble relaxing, irritable, and afraid that something awful might happen during the last 2 weeks related to COVID-19. ${ }^{(9)}$ "Not at all or never," "several or most days," "more than half the days," and "nearly every day" received scores of $0,1,2$, and 3 , respectively. A score of 10 or higher represents a reasonable cutoff point for identifying the cases of anxiety with sensitivity of $89 \%$ and specificity of $82 \%$.

The questionnaires proved to be valid and reliable where the internal consistency represented by Cronbach $\alpha$ was 0.92 and test-retest reliability represented by intra class correlation was 0.83 . In our study, the GAD-7 score was tested for each 
participant as well as the cut-off points for each level, respectively (0-4 minimal anxiety level, 5-9 mild anxiety level, 10-14 moderate anxiety level, and 15-21 severe anxiety level). ${ }^{(9)}$

Lastly, the third part included the General Health Questionnaire-12 (GHQ12); a widely used questionnaire to assess mental health and measure stress. It works as a screening tool for many psychiatric disorders. ${ }^{(10)}$ This scale consists of 12 items with 4 response options. The GHQ-12 has satisfactory reliability as well as good sensitivity and specificity. It was applied to different populations in different countries to study its reliability and validity, and to explore the mental disorders characteristics of the populations in previous studies. The scoring method in this study will be a binary scoring method $(0,0,1,1)$.

A previous study has considered participants who scored 4 or more as having significant distress. ${ }^{(11)}$ A pilot study was conducted on 20 medical students who were not included in the study to assess the feasibility and reliability of the survey, with an acceptable Cronbach's $\alpha$ of 0.7 .

Outcome variables: Anxiety level, psychological stress.

\section{Data Collection:}

Data were collected using an online semi-structured questionnaire using Google forms with a consent included. The consent form was approved by the Vice-dean of the Faculty of Medicine, Suez Canal University where the link of the survey was sent to students through faculty students' Facebook and WhatsApp groups.

\section{Data management:}

The Statistical Package for Social Sciences (SPSS V24.0) was used in statistical analysis. The Shapiro Wilk test checked the normality of data. Mean (standards deviation), frequencies, and percentages were used for descriptive data. Independent student t-test was used for comparisons. Pearson's correlation assessed the correlation between GAD-7 and GHQ12 scores. P-value $<0.05$ was considered statistically significant.

\section{Ethical considerations:}

The ethical committee of Faculty of Medicine, Suez Canal University approved the study (Code 4256\#). After explaining the study purpose and rationale, all students signed written informed consent before participating in the study and without taking any monetary rewards.

\section{Results:}

The study included 381 subjects; the majority of them were females $(59.1 \%)$. Age of the participants ranged from 18 to 28 years old, with mean of 20.5 years. Preclinical years' students fulfilled two thirds of the sample $(n=262,68.8 \%)$ and those 
who had contact with suspected COVID cases were 49 (12.9\%) Table 1.

In table 2 , the mean anxiety score was 9.5, while the mean stress score was 15.4. A number of 136 students (35.7\%) fell into mild anxiety in the previous 2 weeks, 112 (29.4\%) fell into moderate anxiety, and 66 students (17.3\%) had severe anxiety. Regarding psychological stress, about twothirds of the students $(n=244,64.0 \%)$ had more stress in the past 4 weeks.

The students in clinical years experienced more anxiety $(\mathrm{P}=0.017)$ and stress $(\mathrm{P}=0.004)$ compared to the students in pre-clinical study years and those in contact with suspected cases of COVID-19 have more stress $(\mathrm{P}=0.001)$ (Table 3$)$. There is a significant moderate correlation between anxiety and stress scores among study participants $(\mathrm{r}=0.566$ and $\mathrm{P}<0.001)$ (Table 4).

\section{Discussion:}

This study has examined anxiety and psychological stress among medical university students during the COVID-19 pandemic. Psychological stress assessment using the GHQ-12 stress questionnaire reported that students experienced high levels of psychological stress (64\%).

A recent study in Canada found that medical students are frequently subjected to psychological distress and burnout. ${ }^{(12-14)}$ Furthermore, the evolution of the pandemic was found to add more pressure on them, affecting their mental and psychological well-being. ${ }^{(15)}$

Interestingly, a British student published his experience in the midst of the pandemic, pointing out to his distress and suffer with sleep and interaction with others in addition to his worries and also the worries his medical peers. ${ }^{(7)}$

For the anxiety level, the GAD-7 score estimated a mean score of 9.5 where $35.7 \%$ of students were found to have mild anxiety levels, $29.4 \%$ and $17.3 \%$ of them had moderate and severe levels of anxiety, respectively. This result showed good congruence with a recent Brazilian study where the average GAD-7 score for anxiety was 9.18 among their medical students. ${ }^{(16)}$

However, this result is greater than that found among Chinese medical students by Liu et al. where $29.5 \%$ of the participants showed mild level of anxiety, $11.9 \%$ showed moderate levels, and only $2.2 \%$ showed severe ones. ${ }^{(17)}$

This variation may be attributed to the Chinese study's smaller sample size (217 participants) and the research timing as it was conducted shortly after the disease's emergence during the outbreak period when it was not yet a pandemic and the fear of the disease was not at its peak.

Regarding gender, it was found that it has a significant effect on anxiety and 
stress. While Liu et al. and Cao et al. found no significant differences in anxiety prevalence between different genders in their studies among Chinese medical

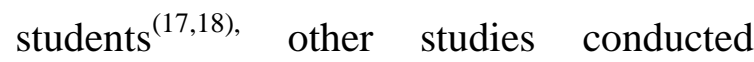
among Brazilian and Vietnamese students found that females had a higher prevalence of anxiety than males. ${ }^{(16,19)}$

In contrast to gender, a significant difference in the prevalence of stress was found among those who had contact with suspected infection $(\mathrm{P}=0.001)$ which could be attributed to the virus's highly contagious nature. ${ }^{(20)}$

Similarly, the differences in the prevalence of anxiety and stress were statistically significant $\quad(\mathrm{P}=0.017$ and $\mathrm{P}=0.004$, respectively) between preclinical and clinical years students where senior students were found to have a higher prevalence rate.

This may be linked to the fact that clinical students are in more contact with patients than pre-clinical ones which might impose more stress on them in addition to the uncertainty regarding their final exams and anticipated graduation. This finding is quite similar to the previous finding of Chandavarkar et al., who found that anxiety symptoms increase when the students move from pre-clinical to clinical years. ${ }^{(21)}$ However, it is opposing to the results found among Turkish and Chinese students ${ }^{(5,17)}$ as differences were not significant regarding the anxiety prevalence between students in different years $(\mathrm{P}=0.220)$.

On studying the correlation between anxiety and stress, the study found that higher stress scores among medical students are associated with more anxiety. This is in agreement with previous literature which mentioned stress as a proposed factor for being depressed and anxious ${ }^{(22)}$ and that the stressful environment impacted the mental health of medical students where anxiety prevails. $^{(13)}$

\section{Study Limitations:}

The study involved students of only one university, so generalization of the results to all medical students cannot be done.

\section{Conclusions:}

The COVID-19 pandemic had a dramatic psychological impact among medical university students. The most affected groups with anxiety and stress were females, students in senior clinical years, and students in contact with suspected COVID-19 cases.

\section{Declaration:}

Authors' Contributions: All authors were equally contributing to this work.

Competing interests: All authors have no competing interests.

\section{Funding: None.}

Acknowledgements: All authors would like to acknowledge all participants for their kind participation. 


\section{References:}

1. CDC. Coronavirus Disease 2019 (COVID-19)-daily life-coping with stress 2020 (updated July1, 2020; cited 20207 July); Available from: https://www.cdc.gov/coronavirus/2019ncov/daily-life-coping/managing-stressanxiety.html.

2. Sahu P. Closure of Universities Due to Coronavirus Disease 2019 (COVID-19): Impact on Education and Mental Health of Students and Academic Staff. Cureus 2020; 12(4): e7541-e. DOI: 10.7759/cureus. 7541 .

3. Giovannella C. Effect induced by the Covid-19 pandemic on students' perception about technologies and distance learning. In Ludic, Co-design and Tools Supporting Smart Learning Ecosystems and Smart Education, Springer publisher 2021; (pp.105-116). DOI: $10.1007 / 978-981-15-7383-5$

4. Rose S. Medical Student Education in the Time of COVID-19. JAMA 2020; 323(21): 2131-2132. DOI: 10.1001/jama.2020.5227.

5. Aker S, Mıdık Ö. The Views of Medical Faculty Students in Turkey Concerning the COVID-19 Pandemic. Journal of Community Health 2020; 45(4): 684688. DOI: 10.1007/s10900-020-00841-9. 6. Al-Rabiaah A, Temsah M-H, Al-Eyadhy AA, et al. Middle East Respiratory
Syndrome-Corona Virus (MERS-CoV) associated stress among medical students at a university teaching hospital in Saudi Arabia. Journal of infection and public health 2020; 13(5): 687-691. DOI: https://doi.org/10.1016/j.jiph.2020.01.00 5.

7. Komer L. COVID-19 amongst the Pandemic of Medical Student Mental Health. International Journal of Medical Students 2020; 8(1): 56-57. DOI: 10.5195/ijms.2020.501.

8. Quek TT-C, Tam WW-S, Tran BX, et al. The Global Prevalence of Anxiety Among Medical Students: A MetaAnalysis. Int $\mathbf{J}$ Environ Res Public Health 2019; 16(15):2735. DOI: 10.3390/ijerph16152735.

9. Spitzer R, Kroenke K, Williams J, et al. Brief Measure for Assessing Generalized Anxiety Disorder: The GAD-7. Archives of internal medicine. 2006; 166:10921097.

DOI:

10.1001/archinte.166.10.1092.

10. Liang $Y$, Wang L, Yin $X$. The factor structure of the 12-item general health questionnaire (GHQ-12) in young Chinese civil servants. Health and Quality of Life Outcomes 2016; 14(1):136. DOI: 10.1186/s12955-0160539-y.

11. Yusoff MS. Effects of a brief stress reduction intervention on medical 
students' depression, anxiety and stress level during stressful period. ASEAN J Psychiatry 2011; 12: 1-14.

12. Maser B, Danilewitz M, Guérin E, et al. Medical Student Psychological Distress and Mental Illness Relative to the General Population: A Canadian CrossSectional Survey. Acad Med 2019; 94(11):1781-1791. DOI: 10.1097/acm.0000000000002958.

13. Voltmer E, Obst K, Kötter T. Studyrelated behavior patterns of medical students compared to students of science, technology, engineering and mathematics (STEM): a three-year longitudinal study. BMC Medical Education 2019; 19(1): 262. DOI: 10.1186/s12909-019-1696-6.

14. Wilkes $\mathrm{C}$, Lewis $\mathrm{T}$, Brager $\mathrm{N}$, et al. Wellbeing and mental health amongst medical students in Canada. International Review of Psychiatry 2019; 31(7-8): 584-587. DOI: 10.1080/09540261.2019.1675927.

15. Ullah R, Amin S. The psychological impact of COVID-19 on medical students [Letter]. Psychiatry Res. 2020 Jun;288:113020.

doi: 10.1016/j.psychres.2020.113020. Epub 2020 Apr 16. PMID: 32315888; PMCID: PMC7160641.

16. Sartorao Filho CI, Rodrigues WCdLV, Beauchamp de Castro R, et al. Impact
Of COVID-19 Pandemic On Menta Health Of Medical Students: A CrossSectional Study Using GAD-7 and PHQ-9 Quetionnairess. medRxiv 2020. DOI: 10.1101/2020.06.24.20138925.

17. Liu J, Zhu Q, Fan W, et al. Online Mental Health Survey in a Medical College in China During the COVID19 Outbreak. Front. Psychiatry, 13 May 2020

| https://doi.org/10.3389/fpsyt.2020.0045 9

18. Cao W, Fang Z, Hou G, et al. The psychological impact of the COVID-19 epidemic on college students in China. Psychiatry Research 2020; 287:112934. DOI: https://doi.org/10.1016/j.psychres.2020 .112934 .

19. Nguyen HT, Do BN, Pham KM, et al. Fear of COVID-19 Scale-Associations of Its Scores with Health Literacy and Health-Related Behaviors among Medical Students. Int J Environ Res Public Health. 2020; 17(11): 4164. DOI: 10.3390/ijerph17114164.

20. Liu Y, Gayle AA, Wilder-Smith A, et al. The reproductive number of COVID-19 is higher compared to SARS coronavirus. Journal of Travel $\begin{array}{lll}\text { Medicine } 2020 ; & \text { 27(2). } & \text { DOI: }\end{array}$ 10.1093/jtm/taaa021. 
21. Chandavarkar U, Azzam A, Mathews CA. Anxiety symptoms and perceived performance in medical students. Depress Anxiety 2007; 24(2): 103-111.

DOI: 10.1002/da.20185.
22. Saravanan C, Wilks R. Medical Students' Experience of and Reaction to Stress: The Role of Depression and Anxiety. The Scientific World Journal 2014; 2014:737382. DOI: $10.1155 / 2014 / 737382$.

Table (1): Socio-demographic characteristics of the sample $($ No. $=381)$

\begin{tabular}{|c|c|c|c|}
\hline \multicolumn{2}{|l|}{ Variable } & No. & $\%$ \\
\hline \multirow[t]{2}{*}{ Gender } & - Male & 156 & 40.9 \\
\hline & - Female & 225 & 59.1 \\
\hline Age (years) & - Mean \pm SD (Range) & \multicolumn{2}{|c|}{$20.5 \pm 1.9$} \\
\hline \multirow[t]{2}{*}{ Faculty Year } & - Pre-clinical & 262 & 68.8 \\
\hline & - Clinical & 119 & 31.2 \\
\hline $\begin{array}{l}\text { Current contact } \\
\text { with suspected } \\
\text { COVID-19 patients }\end{array}$ & $\begin{array}{l}\text { - Yes } \\
\text { - No }\end{array}$ & $\begin{array}{c}49 \\
0.00\end{array}$ & $\begin{array}{l}12.9 \\
0.00\end{array}$ \\
\hline
\end{tabular}


Table (2): Generalized Anxiety Disorder (GAD-7) and Generalized Health Questionnaire (GHQ-12) among medical students (No.=381)

\begin{tabular}{|c|c|c|c|c|}
\hline $\begin{array}{l}\text { Over the last } 2 \text { weeks, how often have } \\
\text { you been bothered by the following } \\
\text { problems }\end{array}$ & \begin{tabular}{|}
$\begin{array}{c}\text { Minimal } \\
\text { (Not at all) }\end{array}$ \\
No. $(\%)$
\end{tabular} & $\begin{array}{c}\text { Mild } \\
\text { (Several } \\
\text { days) } \\
\text { No. }(\%)\end{array}$ & $\begin{array}{l}\text { Moderate } \\
\text { (More than } \\
\text { half the days) } \\
\text { No. }(\%)\end{array}$ & $\begin{array}{c}\text { Severe } \\
\text { (Nearly } \\
\text { every day) } \\
\text { No. }(\%)\end{array}$ \\
\hline - Feeling nervous, anxious, or on edge & $61(16.0)$ & $\begin{array}{c}135 \\
(35.4)\end{array}$ & $101(26.5)$ & $84(22.0)$ \\
\hline $\begin{array}{l}\text { - Not being able to stop or control } \\
\text { worrying }\end{array}$ & $104(27.3)$ & $\begin{array}{c}147 \\
(38.6)\end{array}$ & $83(21.8)$ & $47(12.3)$ \\
\hline - Worrying too much about different things & $67(17.6)$ & $\begin{array}{c}139 \\
(36.5)\end{array}$ & $100(26.2)$ & $75(19.7)$ \\
\hline - Trouble relaxing & $89(23.4)$ & $\begin{array}{c}145 \\
(38.1)\end{array}$ & $96(25.2)$ & $51(13.4)$ \\
\hline - Being so restless that it is hard to sit still & $136(35.7)$ & $118(31.0)$ & $78(20.5)$ & $49(12.9)$ \\
\hline - Becoming easily annoyed or irritable & $80(21.0)$ & $\begin{array}{c}128 \\
(33.6)\end{array}$ & $90(23.6)$ & $83(21.8)$ \\
\hline $\begin{array}{l}\text { - Feeling afraid as if something awful } \\
\text { might happen }\end{array}$ & $79(20.7)$ & $\begin{array}{c}126 \\
(33.1)\end{array}$ & $94(24.7)$ & $82(21.5)$ \\
\hline - Total Anxiety level & $67(17.6)$ & $\begin{array}{c}136 \\
(35.7)\end{array}$ & $112(29.4)$ & $66(17.3)$ \\
\hline $\begin{array}{l}\text { - Total GAD } 7 \text { score }(\text { mean } \pm \text { SD) } \\
\text { (Range) }\end{array}$ & \multicolumn{4}{|c|}{$9.5 \pm 5.5(0-21)$} \\
\hline $\begin{array}{l}\text { - Total GHQ-12 score }(\text { mean } \pm \text { SD) } \\
\text { (Range) }\end{array}$ & \multicolumn{4}{|c|}{$4.7 \pm 3.1(0-12)$} \\
\hline $\begin{array}{l}\text { - Stress (according to GHQ-12) } \\
\text { - No } \\
\text { - Yes }\end{array}$ & \multicolumn{4}{|l|}{$\begin{array}{l}137(36 \%) \\
244(64 \%)\end{array}$} \\
\hline
\end{tabular}


Table (3): Generalized Anxiety Disorder (GAD-7) and Generalized Health Questionnaire (GHQ-12) among medical students according to sociodemographic characteristics

\begin{tabular}{|c|c|c|c|c|c|}
\hline \multicolumn{2}{|l|}{ Variable } & $\begin{array}{c}\text { GAD-7 } \\
\text { Mean (SD) } \\
\text { Range (0-21) }\end{array}$ & $\begin{array}{c}\text { t- test } \\
\text { P- value }\end{array}$ & $\begin{array}{c}\text { GHD-12 } \\
\text { Mean (SD) } \\
\text { Range (0-36) }\end{array}$ & $\begin{array}{c}\text { t- test } \\
\text { P- value }\end{array}$ \\
\hline \multirow[t]{2}{*}{ Gender } & - Male & $8.9(5.3)$ & \multirow{2}{*}{$\begin{array}{c}1.9 \\
0.05\end{array}$} & $14.9(6.6)$ & \multirow{2}{*}{$\begin{array}{c}1.1 \\
0.27\end{array}$} \\
\hline & - Female & $10(5.5)$ & & $15.7(6.2)$ & \\
\hline \multirow[t]{2}{*}{ Faculty Year } & - Pre-Clinical & $9.1(5.2)$ & \multirow{2}{*}{$\begin{array}{c}2.4 \\
0.017 *\end{array}$} & $14.7(6.1)$ & \multirow{2}{*}{$\begin{array}{c}2.9 \\
0.004^{*}\end{array}$} \\
\hline & - Clinical & $10.5(5.9)$ & & $16.7(6.7)$ & \\
\hline \multirow{2}{*}{$\begin{array}{l}\text { Contact with } \\
\text { suspected cases }\end{array}$} & - No & $9.5(5.3)$ & \multirow{2}{*}{$\begin{array}{l}0.82 \\
0.40\end{array}$} & $15.0(6.2)$ & \multirow{2}{*}{$\begin{array}{c}3.2 \\
0.001^{*}\end{array}$} \\
\hline & - Yes & $10.1(6.2)$ & & $18.1(6.9)$ & \\
\hline
\end{tabular}

*statistically significant $(\mathrm{P}<0.05)$

Table 4. Correlation between Generalized Anxiety Disorder (GAD-7) and Generalized Health Questionnaire (GHQ-12)

\begin{tabular}{|l|l|}
\hline Studied variables & GHQ-12 \\
\hline GAD-7 & \\
\hline R & 0.566 \\
\hline P-value & $<0.001 * *$ \\
\hline
\end{tabular}

Pearson's correlation $\quad$ *statistically significant $(\mathrm{P}<0.05)$ 
الملخص العربى

القلق والضغط النفسي أثناء جائحة كوفيد -19 بين طلاب كلية الطب - جامعة قناة السويس- في مصر

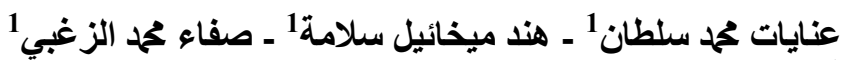

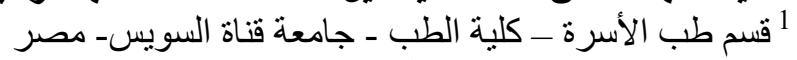

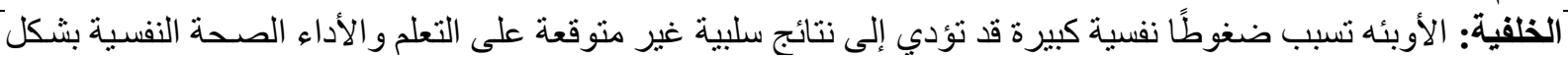

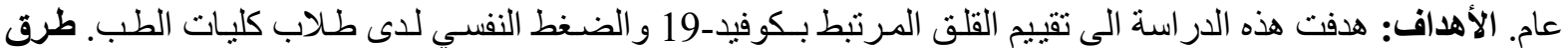

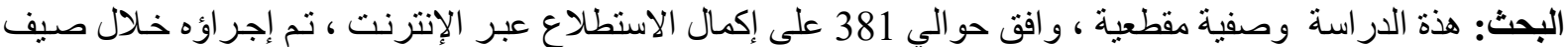

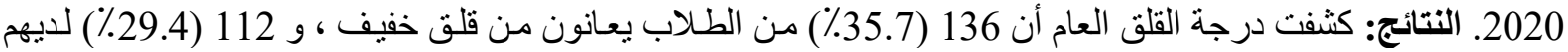

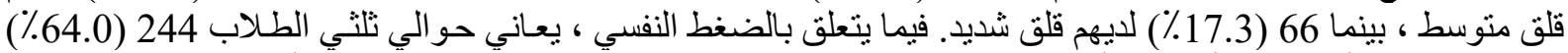

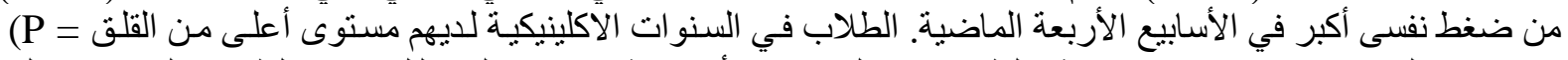

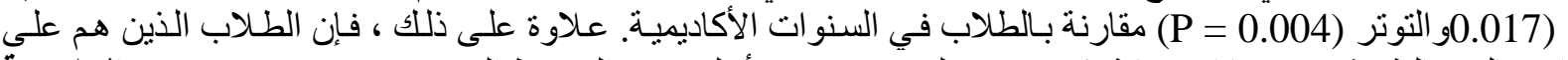

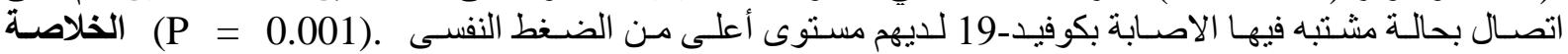

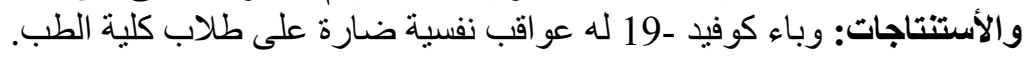

